IdeAs

Idées d'Amériques

$15 \mid 2020$

Eau et gestion de l'eau dans les Amériques

\title{
Do Programa Um Milhão de Cisternas ao Água para Todos: divergências políticas e bricolagem institucional na promoção do acesso à água no Semiárido brasileiro
}

From One Million Cisterns to Water for All Program: political divergences and institutional bricolage in promoting access to water

Du programme Un million de citernes d'eau pour tous : différences politiques et bricolage institutionnel dans la promotion de l'accès à l'eau

Daniela Nogueira, Carolina Milhorance e Priscylla Mendes

\section{OpenEdition}

Journals

Edição electrónica

URL: http://journals.openedition.org/ideas/7219

DOI: 10.4000/ideas.7219

ISSN: 1950-5701

Editora

Institut des Amériques

\section{Refêrencia eletrónica}

Daniela Nogueira, Carolina Milhorance e Priscylla Mendes, « Do Programa Um Milhão de Cisternas ao Água para Todos: divergências políticas e bricolagem institucional na promoção do acesso à água no Semiárido brasileiro », IdeAs [Online], 15 | 2020, posto online no dia 01 março 2020, consultado o 25 março 2020. URL : http://journals.openedition.org/ideas/7219; DOI : https://doi.org/10.4000/ideas 7219

Este documento foi criado de forma automática no dia 25 março 2020.

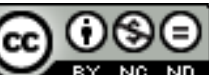

IdeAs - Idées d'Amériques est mis à disposition selon les termes de la licence Creative Commons Attribution - Pas d'Utilisation Commerciale - Pas de Modification 4.0 International. 


\section{Do Programa Um Milhão de Cisternas ao Água para Todos: divergências políticas e bricolagem institucional na promoção do acesso à água no Semiárido brasileiro}

From One Million Cisterns to Water for All Program: political divergences and institutional bricolage in promoting access to water

Du programme Un million de citernes d'eau pour tous : différences politiques et bricolage institutionnel dans la promotion de l'accès à l'eau

Daniela Nogueira, Carolina Milhorance e Priscylla Mendes

\section{Introdução}

1 O Brasil é um país privilegiado no que se refere ao volume de recursos hídricos, detentor de cerca de $13 \%$ da água doce do planeta (Agência Nacional de Águas, 2013). Todavia, a disponibilidade de água no território nacional não é uniforme, e a oferta de água tratada reflete contrastes associados ao processo de desenvolvimento nacional, bem como às desigualdades sociais e regionais dele resultantes. A região Nordeste compreende uma área de $1.670 .000 \mathrm{~km}^{2}$ dos quais $969.589 \mathrm{~km}^{2}$ conformam o chamado Semiárido brasileiro (Figura 1), região historicamente marcada pela ocorrência de secas. 


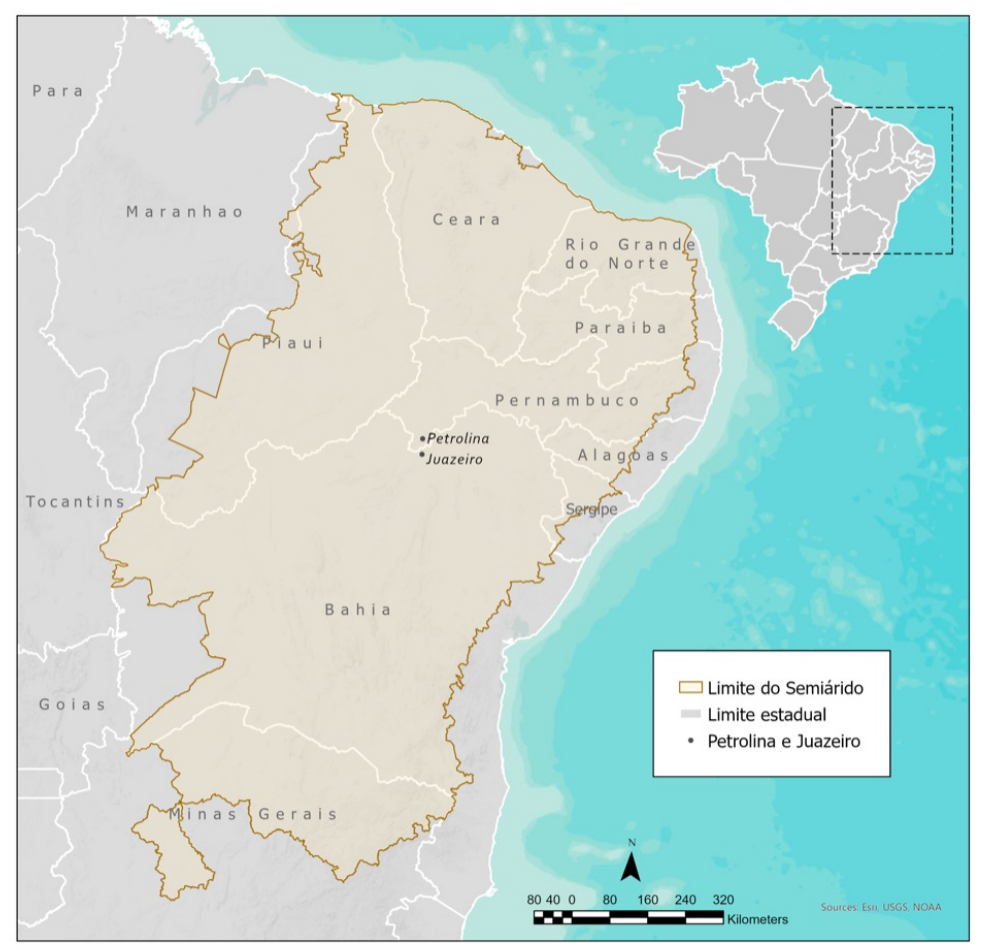

Fonte: Autores, Sudene, 2019.

2 O desenho dos arranjos institucionais e as engrenagens de poder são centrais na configuração das relações de poder. Políticas sociais mais inclusivas e de promoção do acesso à água têm contribuído desde o início dos anos 2000 para reduzir as vulnerabilidades sociais da região, diminuindo as assimetrias de poder existentes. No entanto, ainda é possível observar a existência de uma relação direta entre pobreza e acesso aos serviços básicos (Nogueira D., 2017; Bursztyn M. e Chacon S., 2011).

Uma das principais ações neste contexto é o Programa Um Milhão de Cisternas (P1MC), coordenado pelo Ministério de Desenvolvimento Social e Combate à Fome (MDS) e executado pela rede de organizações da sociedade civil, Articulação do Semiárido (ASA). Lançado em 2003, o programa incluiu iniciativas de formação, educação e mobilização de famílias rurais para construção de cisternas de captação de água da chuva. Ele trouxe importantes resultados no que tange ao desafio de democratizar o acesso à água no Semiárido brasileiro e se destacou por seu desenho metodológico e grau de capilaridade no território (Nogueira D., 2009). Apesar destes resultados, o programa tornou-se um espaço de disputa político-institucional, não apenas entre atores da sociedade civil local e o governo federal, mas também dentro do próprio governo federal. Mudanças significativas na sua concepção e arranjo institucional foram observadas a partir de 2011, com a criação do Programa Água para Todos (APT), no âmbito do Plano Brasil sem Miséria (PBSM). Coordenado pelo Ministério da Integração Nacional (MI), tal mudança provocou transformações no desenho inicial, assim como no processo de implementação do programa e alterou as estratégias privilegiadas de promoção do acesso à água. A transição resultou na formulação de um programa governamental de escala nacional, dotado de orçamento próprio e que incluiu novos 
tipos de infraestrutura hídrica, atraindo assim o interesse de diferentes grupos de poder e diferentes instituições envolvidas na sua implementação.

o presente artigo examina o processo político que levou a tal mudança, trazendo para o centro da discussão suas motivações, evolução e implicações. Além do interesse analítico de um processo de mudança programática e de disputa entre burocracias estatais, incluindo suas dinâmicas de alianças com atores sociais, o artigo discute os desafios de formulação de políticas públicas de acesso à água e de sua implementação em nível local. Por fim, o texto analisa o programa a partir de uma perspectiva mais ampla, destacando os desafios de transpor para a escala nacional iniciativas locais, além de articular tais questões com a redução das vulnerabilidades socioambientais, principalmente no contexto de aumento dos impactos decorrentes das mudanças climáticas.

5 Foram mobilizados dados primários e secundários, incluindo dados bibliográficos e estudos de avaliação dos programas, documentos institucionais, e entrevistas realizadas entre setembro de 2018 e junho de 2019, com gestores públicos e privados, incluindo técnicos e agentes de mobilização de organizações não-governamentais, em Brasília e na região semiárida de Petrolina e Juazeiro, nos estados de Pernambuco e Bahia, respectivamente. Em Brasília, tais gestores fazem parte dos quadros técnicos das instituições federais responsáveis pela formulação e implementação do P1MC e do APT. Já nos estados, estão ligados às unidades gestoras, em algumas ocasiões participando do processo como voluntários.

$\mathrm{O}$ artigo é subdividido em quatro seções. A primeira contextualiza a evolução recente do debate sobre o acesso à água no Semiárido brasileiro. A segunda descreve a emergência e a consolidação do P1MC. Em seguida são trazidas informações de primeira mão sobre a mudança institucional e transição para o APT, listando os principais objetivos e determinantes deste processo. Finalmente, a quarta seção, discute as implicações desta mudança do ponto de vista político e do potencial do programa em reduzir as vulnerabilidades socioambientais na região.

\section{Evolução das respostas político-institucionais ao desafio do acesso à água no Semiárido brasileiro}

$7 \quad 0$ acesso à água é o fio condutor das diversas concepções de desenvolvimento adotadas na formulação de políticas públicas, assim como os ciclos de desenvolvimento econômico que marcaram a região. Políticas decorrentes da "solução hidráulica" ou "açudagem", passando por iniciativas como a estratégia desenvolvimentista, e recentemente, estratégias nacionais mais centralizadoras, foram implementadas em toda a região. No entanto, não priorizavam as particularidades regionais e de forma geral tinham um caráter mais emergencial e menos transformador das estruturas sociais (Nogueira D., 2009; Chacon S., 2007). Algumas dessas políticas públicas acabaram por beneficiar elites locais e reforçar o clientelismo, pois se restringiam a ações pontuais, privilegiando pessoas que já tinham alguma forma de acesso ao poder ou correligionários das oligarquias locais. Corroborando para a manutenção das estruturas de poder existentes na região (Bursztyn M., 2008).

8 Os planos de desenvolvimento macrorregional marcaram a estratégia desenvolvimentista, que prevaleceu entre os anos 1950 e 1970 e levou em consideração, 
de forma mais sistemática, aspectos da estrutura econômica da região. Apesar de ter sido criado no início do século XX, o Departamento Nacional de Obras Contra as Secas (Dnocs) teve um papel importante na construção de grandes reservatórios de água e obras de infraestrutura hídrica. Destaca-se também o papel da Superintendência do Desenvolvimento do Nordeste (Sudene), criada em 1959, que atuou na elaboração de planos regionais de desenvolvimento, com base em uma perspectiva de que a disponibilidade hídrica não significava exclusivamente um problema climático. No entanto, as iniciativas propostas permaneceram baseadas em soluções desconectadas de ações mais enraizadas e geradoras de autonomia e, consequentemente, mais transformadoras da estrutura social e econômica. $\mathrm{O}$ reconhecimento dos limitados resultados das políticas de combate à seca no que se refere à melhoria das condições de vida da população impulsionou o surgimento e atuação de novos atores na construção de alternativas mais sustentáveis para o Semiárido (Milhorance C. et al. 2019b; Nogueira D., 2009).

9 Assim como as políticas desenvolvimentistas, estratégias setoriais também não se apresentaram como propostas de redução das desigualdades e vulnerabilidades sociais. Grandes empreendimentos de geração de energia elétrica têm sido implantados na região, aproveitando o potencial dos recursos naturais locais, como as usinas hidrelétricas no rio São Francisco e, mais recentemente, os parques de energia eólica. Contudo, essas iniciativas pouco contribuíram para a redução dos impactos socioambientais sofridos pelas populações rurais mais vulneráveis (Milhorance C. et al. 2019b). A formulação e implementação dessas iniciativas caracterizaram-se por uma lógica de centralização que acabou por reproduzir a dinâmica de poder já existente e a permanência de entraves à democratização do acesso à água (Nogueira D., 2017).

10 A partir da seca de 1992 a 1993, houve um progressivo reconhecimento dos limitados resultados das políticas de combate à seca no que se refere à melhoria das condições de vida da população rural. Este episódio impulsionou a atuação de novos atores na construção de alternativas de desenvolvimento para o Semiárido. Observa-se uma mudança na reação de organizações da sociedade civil pressionando as autoridades do poder público por ações mais concretas (Cardoso G., 2007). Um conjunto de ações permanentes para convivência com o Semiárido tornou-se objeto de diálogo entre a sociedade civil e o Governo Itamar Franco (1992-1995). O projeto ganhou mais consistência a partir de 1996 por meio das parcerias firmadas com o programa Comunidade Solidária e com a Sudene (Nogueira D., 2009). Todavia, estas permaneceram medidas emergenciais, e o crédito rural para o fortalecimento da infraestrutura hídrica privilegiou os grandes e médios proprietários (Nogueira D., 2009).

11 Um ponto de inflexão institucional neste processo foi o estabelecimento da Política Nacional de Recursos Hídricos (PNRH), preconizada pela Lei 9.433, de 1997, que tem como fundamentos o uso múltiplo das águas e a gestão descentralizada dos recursos hídricos, a partir da participação do poder público, dos usuários e das comunidades. Além de contribuir para a mudança de paradigma referente ao uso e distribuição da água no Brasil, a política estabeleceu como um de seus objetivos o incentivo e promoção da captação, preservação e aproveitamento de águas pluviais, incluindo as cisternas domiciliares.

12 É dentro de um contexto de mudanças políticas na gestão dos recursos hídrico e de insatisfação com as políticas historicamente implementadas na região que, em 1999, 
durante a III Conferência das Partes das Nações Unidas sobre o Combate à Desertificação e Mitigação dos Efeitos da Seca (COP 3) em Recife (PE), representantes de sindicatos de trabalhadores e trabalhadoras rurais, movimentos sociais, entidades religiosas e ONG elaboraram a Declaração do Semiárido. 0 texto trouxe como mensagem central a ratificação de que a adaptação às condições fisiográficas do Semiárido brasileiro era possível (Silva D., 2014; Nogueira D., 2009).

Nesta perspectiva, diversas organizações governamentais e da sociedade civil vêm alterando suas ações de um enfoque de "combate às secas" - caracterizado pelo estabelecimento de grandes infraestruturas hídricas e pela lógica de centralização na gestão dos recursos hídricos - para uma perspectiva de "convivência com o Semiárido". Uma das premissas destas mudanças é assegurar o acesso à água de forma autônoma e descentralizada, garantindo assim a segurança hídrica e alimentar, condições básicas para a permanência das pessoas na região. A evolução institucional da promoção do acesso à água no Semiárido brasileiro, descrita ao longo desta seção, é ilustrada na Figura 2.

Evolução institucional da promoção do acesso à água no Semiárido brasileiro

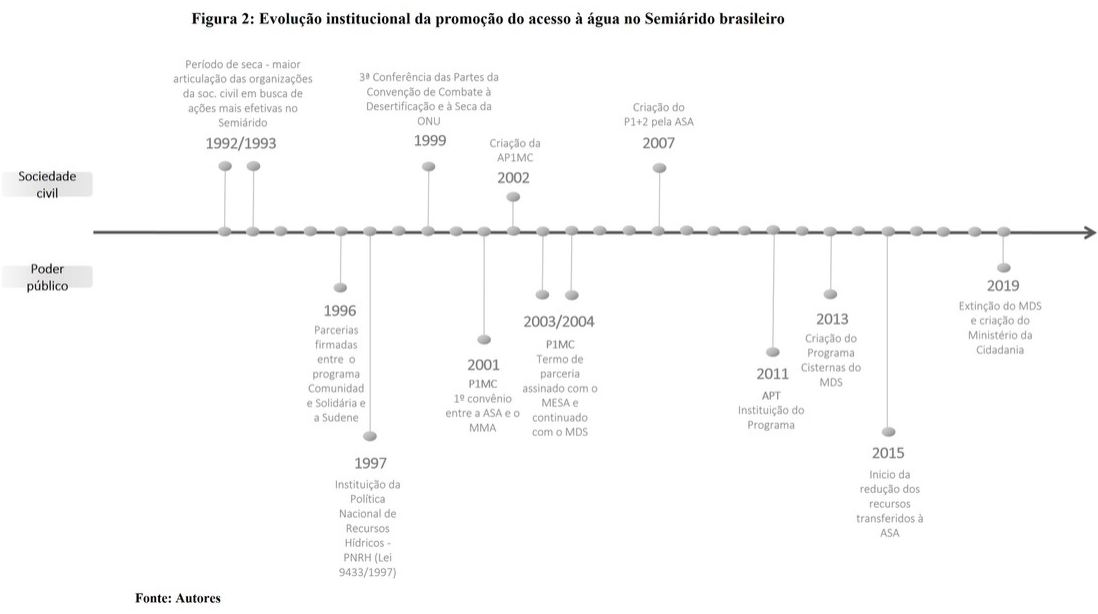

Fonte: Autores

\section{Programa Um Milhão de Cisternas Rurais: institucionalização de uma estratégia de convivência com a seca}

Apesar do aproveitamento da água de chuva para consumo humano e para atividades produtivas ter sido promovido por diversas organizações da sociedade civil do Semiárido desde o início dos anos 1990, sua institucionalização como política pública deu-se em 2003, com a criação do P1MC, durante a presidência de Lula da Silva (2003-2010) (Gandure S.; Walker S. e Botha, J. 2013). O programa destacou-se por seu desenho metodológico, grau de capilaridade, complexidade e, consequentemente, potencial de transformação. A iniciativa inclui formação, educação e mobilização de pessoas e instituições, executado pela ASA, que vem desencadeando um movimento de 
articulação e de convivência sustentável com o Semiárido a partir do fortalecimento da sociedade civil e da construção de cisternas.

15 A ASA é um ator central nesse processo, fruto de uma articulação entre entidades que vinham desenvolvendo iniciativas para promoção de tecnologias sociais no Semiárido, sendo estas realizadas com o apoio da Fundação Grupo Esquel Brasil e da Federação Brasileira dos Bancos (Febraban). Esse processo intensificou-se durante a preparação da COP3 e resultou na criação do Fórum de Articulação do Semiárido (Nogueira D., 2009). No início tratava-se de um grupo relativamente pequeno, formado por organizações de vários estados do Nordeste. A iniciativa expandiu-se e, em 2002, foi criada a Associação Programa Um Milhão de Cisternas (AP1MC), com o objetivo de administrar a implementação do P1MC e repassar os recursos para as Unidades Gestoras Microrregionais (UGM), comissões responsáveis pela execução das ações. Além das UGM, a ASA é composta por uma Comissão Executiva formada pelas entidades diretoras estaduais.

Desde a sua fase inicial, o P1MC contou com várias fontes financiadoras. Dentre as principais, é possível destacar a Agência Nacional de Águas (ANA), a Febraban, a Associação Recife Oxfam para a Cooperação e Desenvolvimento (Oxfam), o Ministério do Meio Ambiente (MMA) e o MDS. o Programa teve início mediante um convênio entre a ASA e o MMA em 2001. Todavia, foi em 2003, por meio de um termo de parceria assinado com o então Ministério Extraordinário de Segurança Alimentar e Combate à Fome (MESA) ${ }^{1}$, que o P1MC ganhou impulso.

17 Entre 2003 e 2010, 329.569 cisternas de placas para abastecimento humano foram construídas no âmbito do P1MC (MDS 2016). Entre as principais vantagens dessa infraestrutura destacam-se a qualidade da água, a proximidade da residência e o custo relativamente baixo - cerca de $\mathrm{R} \$ 3$ mil, que inclui material, mão-de-obra, mobilização e capacitação das famílias beneficiadas com a tecnologia (Santana V. et al. 2011). 0 uso da água armazenada nas cisternas residenciais deve ser exclusivo para o abastecimento humano, não sendo suficiente para atender outras necessidades durante a seca. Tratase de uma alternativa ao alto custo dos carros-pipa e à falta de garantia da qualidade da água de outras fontes de abastecimento, como açudes, sendo também usada como reservatório para armazenamento nos períodos de seca, principalmente nas regiões mais distantes dos aglomerados comunitários (Andrade T. et al. 2015; Nóbrega R. et al. 2013).

Portanto, o P1MC trouxe inovações metodológicas e de gestão ao desafio histórico de democratizar o acesso à água no Semiárido brasileiro. O programa ganhou reconhecimento nacional e internacional como estratégia de superação da pobreza rural na região. No entanto, sua capacidade de execução e universalização do acesso à água foi considerada baixa por membros do governo federal. Neste contexto, o P1MC vem assumindo diferentes contornos ao longo dos anos, resultado da experimentação $\mathrm{e}$ do diálogo - nem sempre harmonioso (Nogueira D., 2017) -entre atores da sociedade civil local e do governo federal, que contribuíram para moldá-lo (Bonnal P. e Piraux M. 2010). Mudanças mais importantes na sua concepção e no seu arranjo institucional ocorreram a partir da criação do programa APT, e serão discutidas nas próximas seções. 


\section{O Programa Água para Todos e a proposta de universalização do acesso à água}

\section{Objetivos, governança e implementação}

19 O Programa APT foi instituído em julho de 2011 pelo governo federal, no contexto do Plano Brasil Sem Miséria (PBM), com a proposta de universalizar o acesso à água na zona rural. Considerado uma das principais bandeiras políticas do governo Dilma Rousseff (2011-2016), a principal diretriz do PBM é a priorização da população em situação de extrema pobreza, ampliando o acesso aos serviços públicos e também a oportunidades de ocupação e renda. O APT tem como objetivo garantir o amplo acesso à água para as populações rurais dispersas e em situação de extrema pobreza, seja para o consumo próprio ou para a produção de alimentos e a criação de animais, possibilitando a geração de excedentes comercializáveis para a ampliação da renda familiar dos produtores rurais (MI 2012).

O APT combinou iniciativas existentes de disseminação de infraestruturas e tecnologias hídricas, mas com maior número de parcerias e diferentes arranjos institucionais. A principal tecnologia apoiada é a cisterna para captação de água da chuva para abastecimento humano, seja de placas de cimento ou de polietileno. A estratégia de captação e armazenamento de água da chuva no Semiárido foi preconizada pela PNRH no final dos anos 1990, mas tornou-se uma estratégia política relevante apenas nos anos 2000, promovendo o acesso descentralizado e territorializado à água (Campos A. e Melo Alves A. 2014). A inovação na utilização das cisternas de placas no âmbito do P1MC foi o desenho metodológico, que incluiu formação dos beneficiários para construção e manutenção das cisternas e organização social na gestão dos recursos hídricos, e o arranjo institucional de implementação, que envolveu parcerias entre o governo federal e organizações da sociedade civil local (Pereira M., 2016).

21 Com a constituição do APT, o governo federal pretendia ampliar significativamente a instalação de cisternas, tendo como meta entregar 750 mil em um período de menos de quatro anos, o que exigia mudanças importantes no desenho institucional e uma maior articulação entre atores (Campos A. e Melo Alves A. 2014). Além de incluir novos órgãos, como o MI, o MMA, a Fundação Nacional de Saúde (Funasa), e a Fundação Banco do Brasil (FBB), foram assinados contratos de prestação de serviços com o Banco do Nordeste do Brasil (BNB), e firmados convênios com consórcios públicos de municípios, que até então não participavam do processo.

Quanto às tecnologias apoiadas, o governo ampliou suas opções, incluindo a cisterna de polietileno, tecnologia promovida pelo MI. A operacionalização da compra e instalação dessas cisternas foi viabilizada pela Companhia de Desenvolvimento dos Vales do São Francisco e do Parnaíba (Codevasf) e pelo Dnocs, por meio de convênios com estados e licitação para contratar empresas privadas, nas quais duas multinacionais saíram vencedoras. Além disso, foram incorporadas novas infraestruturas, tais como sistemas coletivos de abastecimento e tecnologias de água para produção, como pequenas barragens, cisternas calçadão, barreiros e kits de irrigação.

$\mathrm{O}$ argumento do governo para promover o modelo de fabricação e instalação das cisternas de polietileno foi a celeridade na implementação do programa, em comparação com as cisternas de placa. Segundo os gestores, tal decisão foi embasada pela existência de outras experiências com o produto em países como México, 
Austrália, Nova Zelândia, Estados Unidos, Malásia e Indonésia, e regiões com alta incidência solar, à semelhança da região do Semiárido brasileiro. Além disso, estudos realizados pelo MI indicavam que as cisternas de placa teriam demonstrado alta durabilidade -cerca de 20 anos- e sua instalação era considerada mais simples que as de placa (MI 2011).

No entanto, foram várias as críticas a esta escolha. Neste contexto, a ASA lançou em 2011 a campanha "Cisterna de Plástico/PVC - Somos Contra!". Segundo representantes da rede, a mudança para o APT resultou na concentração de recursos financeiros, menor capacidade de dinamização da economia local, além da inadequação da tecnologia escolhida às características produtivas da região. Além disso, a cisterna de polietileno excluía a componente de formação e mobilização das famílias rurais para a convivência com o Semiárido (Pereira M., 2016; ASA 2011). Mais do que uma mudança metodológica, observou-se uma mudança na configuração política do programa. Segundos diversos atores que estiveram à frente do processo de resistência, uma maior celeridade na implementação do P1MC poderia ter sido mais facilmente alcançada mediante a desburocratização dos repasses financeiros aos agentes envolvidos, bem como por meio do aumento dos recursos destinados às unidades executoras da sociedade civil, uma vez que estas já eram detentoras da expertise necessária à governança e à execução do programa.

paralelo à execução da instalação das cisternas de polietileno pelo MI, a instalação das cisternas de placas continuou sendo executada pelo MDS, depois de impasses na negociação com a ASA. Posteriormente, em outubro de 2013, o governo federal instituiu o Programa Nacional de Apoio à Captação de Água de Chuva e Outras Tecnologias Sociais de Acesso à Água (Programa Cisternas), dando força de lei às ações de implementação de cisternas pelo MDS. Além do abastecimento humano, o Programa Cisternas tem como finalidade promover o acesso à água para produção alimentar, por meio de cisternas produtivas. No caso das cisternas de produção, tal tecnologia já estava sendo difundida pela ASA desde 2007, por meio do Programa Uma Terra e Duas Águas (P1+2), com o objetivo de promover a segurança alimentar e nutricional das famílias agricultoras, além de estimular a geração de emprego e renda (ASA 2019) objetivos que se alinham diretamente com o propósito central do APT.

Após muitos embates e alguns ajustes, o novo arcabouço institucional buscou simplificar os processos de contratação e prestação de contas pelas organizações da sociedade civil. Uma das principais mudanças foi a possibilidade de formalizar contratos por dispensa de licitação com entidades privadas sem fins lucrativos previamente credenciadas pelo MDS. Este marco contribuiu para institucionalizar um modelo de governança da política que fortalece a relação entre Estado e sociedade civil na execução de políticas públicas e trouxe inovações importantes para a superação de entraves burocráticos.

27 A Tabela 1 resume os atores e instrumentos legais de cada programa e a Tabela 2 informa as tecnologias de captação da água entregues por estes programas. Os dados foram organizados entre os períodos anterior (2003 a 2010) e posterior (2011 a 2016) à criação do Programa APT. Vale notar que as informações sobre impactos de cada programa no aumento do acesso à água e no fortalecimento da capacidade de convivência com o semiárido não estão disponíveis. No entanto, no que se refere especificamente à instalação de cisternas, os dados mais recentes de implementação do APT indicam um aumento substancial do número inicial. No período de 2011 a fevereiro 
de 2016, mais de um milhão de cisternas de consumo (placas e polietileno) e de produção foram entregues. Este número é cerca de três vezes maior que as cisternas implantadas entre os anos de 2003 e 2010. Se compararmos apenas as cisternas de produção nos dois períodos citados, esse aumento chega a ser 20 vezes maior (MDS 2016). Segundo dados do Ministério do Planejamento, em 2017, mais de $47 \mathrm{mil}$ tecnologias sociais de acesso à água para consumo humano foram entregues, incluindo comunidades indígenas, e quase onze mil de água para produção agrícola (MPDG 2017). Os dados após este período são pouco sistematizados, criando uma lacuna de informação para o acompanhamento destas ações. Apesar disto, a última seção deste artigo discute alguns dos resultados e limites de cada programa.

Tabela 1 Quadro síntese dos programas federais para universalização do acesso à água no Semiárido brasileiro

\begin{tabular}{|c|c|c|c|}
\hline & P1MC & APT & Programa Cisternas \\
\hline $\begin{array}{l}\text { Principais } \\
\text { tecnologias } \\
\text { hídricas } \\
\text { disseminadas }\end{array}$ & $\begin{array}{l}\text { Cisternas de placa } \\
\text { de abastecimento } \\
\text { humano (16 mil } \\
\text { litros) }\end{array}$ & $\begin{array}{l}\text { Cisternas de polietileno de } \\
\text { abastecimento humano (16 mil } \\
\text { litros), barreiros, cisternas } \\
\text { produtivas } \\
\text { enxurrada, etc.) (52 mil litros), } \\
\text { pequenas barragens, kits de } \\
\text { irrigação }\end{array}$ & $\begin{array}{l}\text { Cisternas de placas de } \\
\text { abastecimento humano } \\
\text { (16 mil litros), cisternas } \\
\text { produtivas (calçadão, } \\
\text { enxurrada, etc.) (52 mil } \\
\text { litros) }\end{array}$ \\
\hline $\begin{array}{l}\text { Marco legal e } \\
\text { modalidades de } \\
\text { parceria }\end{array}$ & $\begin{array}{l}\text { Termo de Parceria } \\
\mathrm{N} \circ 01 / 2003\end{array}$ & $\begin{array}{l}\text { Convênios com entidades } \\
\text { privadas, instituições regionais, } \\
\text { estados e municípios } \\
\text { Decreto } \mathrm{n}^{\mathrm{o}} 7.535 \text {, de } 26 \text { de julho } \\
\text { de } 2011 \text {, alterado pelo Decreto } \\
\mathrm{n}^{\circ} 8.039 / 2013\end{array}$ & 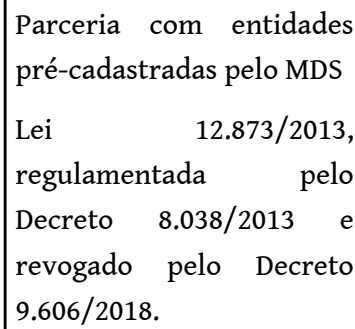 \\
\hline $\begin{array}{l}\text { Instituição } \\
\text { coordenadora }\end{array}$ & ASA/MDS & MI & MDS \\
\hline $\begin{array}{l}\text { Principais } \\
\text { instituições } \\
\text { envolvidas na } \\
\text { execução }\end{array}$ & ASA & $\begin{array}{l}\text { MDS, MI, Codevasf, DNOCS, } \\
\text { MMA, ANA, Funasa, FBB, } \\
\text { BNDES, Petrobras e a ASA }\end{array}$ & ASA e prefeituras \\
\hline
\end{tabular}

Fonte: Autores

Tabela 2 Tecnologias de captação de água de chuva entregues no Semiárido, por tipo de tecnologia e período

\begin{tabular}{|l|l|l|}
\hline & 2003 a 2010 & 2011 a 2016 \\
\hline Consumo humano & 329.569 & 928.101 \\
\hline Produção & 7.505 & 162.032 \\
\hline
\end{tabular}




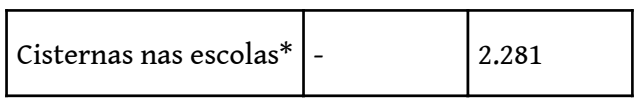

Fonte: MDS, 2017

*Iniciativa iniciada em 2015

\section{Processo de formulação, ajustes e bricolagem institucional}

críticas no que se refere à simplificação do seu desenho metodológico e até mesmo de uma descaracterização de seus elementos mais inovadores. Estes incluíam o envolvimento e a capacitação das famílias beneficiadas, focalização em famílias chefiadas por mulheres, dinamização da economia local e descentralização do modelo de governança mediante o fortalecimento da sociedade civil local. Tais críticas reforçaram a pressão para que a coordenação do APT realizasse ajustes no seu desenho, aproximando-o dos componentes mais inovadores que constavam no P1MC. No entanto, dada a escala geográfica de implementação e a complexidade de seu arranjo

Com a criação do APT, o governo federal buscava aplicar um ritmo mais acelerado de execução e instalação de tecnologias de captação de água. O MI, cuja missão passava pela diminuição das desigualdades regionais mediante a garantia do acesso à água, foi indicado pelo governo Rousseff para coordenar a articulação de iniciativas governamentais já existentes, mas até então fragmentadas em diversos setores e ministérios, dentre eles desenvolvimento regional, agricultura, desenvolvimento rural, cidades e meio ambiente. concentra o maior número de famílias em situação de vulnerabilidade. Posteriormente, o Comitê Gestor deliberou pela inclusão de aposentados rurais que não estivessem no Cadastro Único para Programas Sociais do Governo Federal (CadÚnico), assim como de alguns municípios com escassez hídrica fora dos limites oficiais do Semiárido. Estes estavam localizados nos estados do Amazonas, Espírito Santo, Goiás, Maranhão, Pará, Rio Grande do Sul, Santa Catarina e Tocantins.

instituições envolvidas, no padrão de alocação de recursos federais, e na metodologia e no objetivo final do APT em relação ao P1MC, gerando críticas dentro e fora do governo. Do ponto de vista institucional e financeiro, o MDS perdeu parte substancial do orçamento da Secretaria Nacional de Soberania Alimentar e Nutricional e de sua autonomia na aplicação de tais recursos. Na sociedade civil, as críticas vieram, sobretudo, da ASA, que teve seu orçamento reduzido, e sofreu o impacto da perda de autonomia do MDS na execução. Além disso, viu sua centralidade institucional e programática se fragmentar com o aumento de órgãos executores, diversificação de tipos de infraestrutura e pulverização de recursos. assumido pelos municípios. A inclusão de um leque mais amplo de atores no APT contribuiu, de um lado, para a complexificação do arranjo institucional do programa; e de outro, para a retomada do protagonismo dos municípios e, consequentemente, das elites locais na (re)configuração do desenho de novos pactos políticos em torno da água. 
institucional, os ajustes configuraram-se mais como uma bricolagem institucional do que com um novo desenho de fato (Nogueira D., 2009), isto é, a elaboração de um 'novo' desenho metodológico inspirado em alguns componentes do P1MC foi uma tentativa de dar uma resposta rápida às duras críticas recebidas, mas que na prática pouco guardou do seu conteúdo original em seu processo de implementação, particularmente, no que se refere ao seu potencial de transformação e democratização do acesso à água.

Essa bricolagem institucional configurou-se, portanto, como novo arranjo de política que combinou elementos do "moderno" - ao buscar manter um modelo de governança descentralizado e participativo fundamentado no desenho do P1MC - e do "tradicional" - ao dialogar com as oligarquias locais, incialmente não incorporadas na etapa de implementação. Vale notar que estas oligarquias foram reconhecidas como atores centrais em sua governança. Além disso, o novo arranjo mesclou componentes e regras "formais", ao reproduzir a estrutura de governança proposta no novo desenho, e "informais", ao ignorar alguns dos critérios de priorização existentes. Este processo de bricolagem materializou a reprodução de uma série de divergências políticoinstitucionais e de diferentes concepções de desenvolvimento na elaboração das políticas públicas e acabou por não operar a desejada ruptura nas assimétricas relações de poder que permeiam as iniciativas de acesso à água no Semiárido.

\section{Discussão}

\section{Divergências políticas e concepções de desenvolvimento}

Parte das reações ao APT se deu em torno das características das tecnologias priorizadas, principalmente no que se refere às diferenças entre as cisternas de placas e de polietileno. A ASA trouxe para o debate uma série de críticas às cisternas de polietileno. Dentre elas, sua baixa capacidade de dinamização do desenvolvimento local, uma vez que a compra de grandes lotes de cisternas de poucas empresas contribuiria para a concentração de rendimentos. Em contraste, o processo de construção de cisternas de placas foi reconhecido por seu potencial de gerar renda de forma desconcentrada para pedreiros, mobilizadores comunitários e técnicos de ONG, além de movimentar a economia local, onde são comprados os materiais de construção (ASA 2011).

Críticas semelhantes surgiram também na academia. Estudos mostraram o potencial do P1MC em promover uma reflexão sobre a gestão e o manejo comunitário dos recursos hídricos e a articulação com organizações da sociedade civil de base local (Silva D., 2017; Pereira M., 2016). A participação das famílias é considerada relevante para a apropriação da tecnologia no processo de captação da água, garantia de sua qualidade e manutenção do sistema no longo prazo (Pereira M., 2016; Nogueira D., 2013).

A qualidade do material também foi questionada. Argumentou-se, por exemplo, que as cisternas de polietileno não seriam adequadas à região semiárida por não resistirem às altas temperaturas, resultando em deformação do material e aquecimento da água armazenada (Pereira M., 2016). Vale notar que algumas desvantagens das cisternas de placas foram mencionadas, cabendo destaque para o fato do processo de construção exigir pedreiros qualificados (Nogueira D., 2013), possibilidade de fissuras por onde a água vaza, e necessidade de intervalo de três semanas entre a fabricação das placas e o início do levantamento das paredes (Gnadingler J., 1999). 
38 No entanto, os estudos comparativos entre as duas tecnologias ainda são pouco conclusivos. Por exemplo, no estado do Ceará houve divergência entre regiões (Trairi e Caucaia) quando os beneficiários foram questionados sobre a melhor solução (cisternas de placa ou polietileno) para o abastecimento de água (Schmitt J., 2015). No estado do Rio Grande do Norte, estudos indicaram uma rejeição do público à cisterna de plástico, alegando menor durabilidade do produto industrializado e orientação inadequada quanto ao manejo da água (Morais H.; Paiva, J. e Souza, W. 2017). Nos estados de Bahia e Pernambuco (Juazeiro e Petrolina), entrevistas realizadas em maio de 2019 indicaram certa preferência pelas cisternas de polietileno no que se refere à manutenção da qualidade da água armazenada. Por outro lado, a maior parte destas cisternas não se encontrava conectada aos telhados e era utilizada como reservatório para água distribuída por caminhão-pipa ou poços artesianos, enquanto as cisternas de placa estavam em sua maioria conectadas aos telhados das casas. A justificativa recorrente para a desconexão dos telhados é a ausência ou insuficiência de chuva. Ainda sim, predomina a percepção dos gestores e beneficiários de que a possibilidade de utilização como reservatório é um grande avanço, pois possibilita o armazenamento de água próximo à residência. Tudo isso indica falhas na implementação dos programas, especialmente no que se refere ao monitoramento ou mesmo à ausência de uma avaliação ex-post.

Uma série de instituições gestoras entrevistadas também demonstraram preferência em relação às cisternas de placa. O MDS ratificou as vantagens já elencadas nesse trabalho: geração de emprego e renda, baixo custo, comparado com as cisternas de polietileno. A Codevasf destacando o menor custo em relação às de polietileno. Enquanto a FBB tomou uma decisão técnica de apoiar a cisterna de placas no âmbito de seus projetos.

Os estudos mencionados de avaliação de impacto englobam um número muito limitado de beneficiários e de localidades, e são pouco sistemáticos. Estudos mais amplos e aprofundados seriam necessários para melhor embasar este debate. Ainda assim, mesmo os estudos mais favoráveis às cisternas de polietileno recomendam uma revisão dos mecanismos de instrução que fortaleça as aptidões das famílias na manutenção e higienização do sistema, além de uma análise mais aprimorada das condições de acesso à água em cada microrregião (Schmitt J., 2015; Mota D.; Vianna M. e Lacerda K. 2016).

41 Mais do que uma divergência sobre o potencial e os limites das tecnologias de armazenamento de água, a mudança no desenho original do P1MC resultou em mudanças políticas e alteração no papel de cada instituição envolvida. Com o lançamento do APT, a parceria com a ASA foi brevemente interrompida. $O$ atrito entre a ASA e o governo federal deu-se num contexto de divulgação de escândalos de desvio de recursos públicos envolvendo convênios com ONG e o Ministério do Esporte. Apesar de não haver nenhum indício de irregularidades por parte da AP1MC e este modelo de parceria ter sido considerado transparente por diversos analistas (Pereira M., 2016), as regras relativas às transferências de recursos da União foram alteradas.

Segundo representantes do MI, o apoio à distribuição de infraestruturas descentralizadas de acesso à água ilustrava uma gradual incorporação da lógica de “convivência com o Semiárido" nas ações deste ministério (De Nys E. e Engle N. 2014). Todavia, de acordo com representantes da ASA e alguns pesquisadores, a persistência das cisternas de plástico significava uma nova versão da lógica de "combate à seca", dada a concentração de recursos em poucos fornecedores, o baixo envolvimento das 
famílias e das organizações da sociedade civil, e a transferência de tecnologias desenvolvidas em outros países e não necessariamente adaptadas às condições ambientais do Semiárido (Pereira M., 2016; ASA 2011).

Diante da pressão da sociedade civil e de membros do governo, os convênios foram retomados por meio do Programa Cisternas, apresentado na seção anterior. No Programa APT, a distribuição de cisternas de polietileno pela Codevasf, Dnocs e Funasa foi mantida. Além disso, foi definido um critério de contratação de empresas que utilizassem mão de obra local tanto na produção quanto na implementação de cisternas. Neste contexto, uma multinacional mexicana que ganhou a licitação para o primeiro lote de cisternas, construiu fábricas em Petrolina-PE, Penedo-AL, Teresina-PI e Montes Claros-MG. O MI também buscou estabelecer um desenho e modelo de interlocução com os parceiros e beneficiários inspirado no modelo da ASA/MDS, o que incluiu a criação de comitês gestores estaduais e municipais. Todavia, estes não contavam com a mesma capilaridade institucional das UGM da ASA, o que dificultou a implementação do novo desenho e facilitou a reprodução da lógica já existente (MDS 2015).

Em resumo, o processo descrito neste artigo ilustra uma série de mudanças incrementais (Lindblom C., 1979) baseadas em disputas, negociações e colaboração entre o governo federal e organizações da sociedade civil no que se refere à concepção e às formas de implementação dos programas de acesso à água. A distribuição dos recursos hídricos envolve disputas políticas e controvérsias em torno das distintas concepções de desenvolvimento do Semiárido nordestino. Ao longo do tempo, os programas foram passando por mudanças incrementais, fruto da dupla relação de colaboração e oposição entre o governo e as organizações da sociedade. Houve interrupções do programa, principalmente em função de alterações das regras de repasse e uso de recursos públicos.

No entanto, cabe mencionar que, sem a parceria do governo federal e do setor privado (por meio da Febraban), dificilmente o P1MC alcançaria a atual abrangência em todo o Semiárido. Por outro lado, a interação entre os atores locais envolvidos no P1MC e os órgãos públicos municipais, em especial as prefeituras, tem sido baixa. Este cenário estaria relacionado à preocupação em se distanciar de possíveis capturas clientelistas. A participação das prefeituras mostrou-se importante para transpor gargalos do programa em diversas circunstâncias, porém estas interações não foram suficientemente adensadas (Andrade J. e Cordeiro J. 2016).

\section{Por uma abordagem com base nas vulnerabilidades socioambientais}

Independentemente do arranjo institucional, as cisternas apresentam-se como uma alternativa na garantia ao acesso à água para o abastecimento humano e a pequena produção, aumentando assim a segurança hídrica das famílias rurais que vivem afastadas dos aglomerados comunitários. Trata-se de uma estratégia de baixo custo, e impacto ambiental praticamente nulo quando comparado ao impacto gerado pelas grandes obras de infraestrutura hídrica historicamente priorizadas na região. No entanto, as cisternas não constituem soluções definitivas para as questões da vulnerabilidade social e climática no Semiárido, pois nem sempre há água suficiente para enchê-las. Tal característica tem colaborado para a perpetuação de políticas 
emergenciais como a dos carros-pipa e ressalta a necessidade da continuidade dos investimentos em infraestrutura e formação. Neste contexto, tanto o P1MC quanto o APT devem ser considerados como iniciativas absolutamente relevantes e necessárias, mas não suficientes para o atingimento da segurança hídrica das famílias sertanejas.

De fato, a meta de universalização torna o Programa APT uma iniciativa de grande relevância na direção da garantia do direito humano ao acesso à água. Entretanto, a redução das vulnerabilidades socioambientais requer abordagens mais amplas que vão além da distribuição de infraestruturas hídricas. São necessárias abordagens integradas para enfrentar os desafios da multidimensionalidade da pobreza.

Aspectos como o avanço nas condições de saúde, educação, redução do tempo e esforço gastos nos deslocamentos para a obtenção de água, tarefa executada principalmente por mulheres e meninas de diferentes idades, têm sido reconhecidos por diversos estudos e autores (Nogueira D., 2013; Pereira M., 2016; TCU 2006). Em Pernambuco e na Paraíba, houve uma diminuição da evasão escolar de meninas nos períodos da seca (Nogueira D., 2009). Na Bahia observou-se, por exemplo, uma redução da mortalidade por diarreia e outras causas evitáveis. Contudo, a mortalidade proporcional por estas causas permanece elevada e sua redução requer intervenções multissetoriais por meio da articulação de políticas que enfrentem de forma mais abrangente seus determinantes sociais (Rasella D., 2013). Por exemplo, a integração entre políticas sociais e sanitárias com as políticas habitacionais, de inclusão produtiva e ações regulares de controle da qualidade da água armazenada é considerada fundamental (Andrade J. e Nunes M. 2017). Para captar o volume de água suficiente para encher a cisterna, é necessário que o telhado da residência esteja em boas condições estruturais e possua área de pelo menos $40 \mathrm{~m}^{2}$, o que não representa uma realidade em todo Semiárido (Andrade J. e Nunes M. 2017).

O cruzamento de informações das bases de beneficiários do APT e de outras ações do PBM (por meio do CadÚnico) sugere que muitas famílias foram incluídas num processo mais amplo de superação da situação de extrema pobreza. A condicionalidade da instalação de cisternas de abastecimento doméstico para a instalação de cisternas produtivas por meio do Programa P1+2 também denota uma atuação mais integrada por parte do governo federal na ampliação do acesso à água no Semiárido. Outras políticas públicas foram sendo agregadas nesse contexto, ampliando o acesso das famílias beneficiárias a serviços públicos, como a emissão de documentos pessoais de identificação e ações de assistência técnica e extensão rural por meio do Programa Fomento do MDS. No entanto, uma série de fatores políticos e operacionais limita o aprofundamento deste tipo de abordagem (Milhorance C. et al. 2019a).

50 Além do mais, a relativa autonomia dos agentes implementadores das cisternas de placa leva a resultados positivos em termos de apropriação das tecnologias e de articulação das políticas de redução da pobreza. Estudos têm mostrado, por exemplo, o papel informal dos agentes locais na articulação destas ações com políticas de acesso ao crédito rural e de vendas institucionais da agricultura familiar (Milhorance C. et al. 2019a).

51 Além do desafio de integração programática, uma questão adicional na redução das vulnerabilidades socioambientais é o avanço das mudanças climáticas e dos processos de desertificação em curso no Semiárido (Martins M. et al. 2017; Silva B. et al. 2019; Marengo J. et al. 2019). Estes cenários indicam desafios crescentes e maior complexidade no atendimento das demandas de água, principalmente, das populações 
rurais difusas. Além disso, as desigualdades no acesso à água podem exacerbar ainda mais as clivagens de gênero (Nogueira D., 2013), étnico-raciais e geracionais já existentes (Nogueira D., 2017; Pereira M., 2016).

Neste contexto, a perspectiva da adaptação às mudanças climáticas não pressupõe um retorno às soluções hidráulicas orientadas pela percepção de que a questão da seca se limita ao fenômeno climático. Pelo contrário, ela integra questões sociais estruturais em que os condicionantes naturais estão imbricados com os de natureza humana e principalmente política. Princípios de equidade estão estreitamente relacionados à identificação das vulnerabilidades. $\mathrm{O}$ foco nas questões de governança e tomada de decisão é considerado fundamental para promoção da capacidade adaptativa, especialmente num contexto de assimetrias de poder e no acesso aos recursos (Adger N., 2006). Parte desta literatura argumenta ainda que as intervenções políticas devem reconhecer a pluralidade de tipos de conhecimento e de sistemas de governança que são usados para gerenciar riscos e promover a resiliência (Adger N., 2006).

Estudos têm mostrado a necessidade de se adaptar as características das cisternas em determinadas regiões, por exemplo, a área do telhado (área de captação) e o dimensionamento da cisterna, para que a população local tenha acesso à água mínima necessária para uso. As medidas de manejo assinadas para atender ao déficit hídrico da população semiárida devem ser adequadas à realidade de cada localidade. Isso permitirá, além da aplicação de tecnologias mais eficientes para as características locais, maior economia na implementação das medidas de gestão propostas (Rodriguez R. et al. 2016). Sistemas de policulturas também são reconhecidos por garantir maior segurança alimentar em contextos de instabilidade ambiental. Portanto, a articulação entre a disseminação de cisternas produtivas e práticas de produção agrícola mais resilientes é fundamental neste processo.

Por fim, mais do que uma estratégia de convivência baseada no aprendizado sobre o histórico do clima na região, será preciso incorporar às políticas de promoção do acesso à água no Semiárido os impactos já conhecidos e as projeções de aumento da variabilidade climática. Tal consideração é coerente com posições de determinados atores institucionais, por exemplo, de representantes do Ministério da Fazenda. Além de incorporar as projeções climáticas no planejamento público, o representante entrevistado destacou a necessidade de se rever o investimento em ações emergenciais que se tornaram rotineiras, com base nestas projeções. No entanto, tal percepção ainda não é difundida ou materializada no âmbito da administração pública.

Outro exemplo é a redefinição do valor de construção das cisternas instaladas pela FBB para incluir o abastecimento com uma carga de água por carro-pipa. Tal opção foi reativa aos impactos da seca de 2012-2016, possivelmente associados à intensificação de eventos climáticos extremos associada às mudanças climáticas globais. Portanto, além dos desafios político-institucionais decorrentes das mudanças programáticas e metodológicas observadas na transição do P1MC ao APT, novos desafios se impõem às políticas de promoção do acesso à água no Semiárido. Além da capacidade de integração das intervenções em um mesmo território, será importante incorporar o debate das alterações climáticas no próprio planejamento das políticas públicas, estabelecendo maior flexibilidade institucional a fim de garantir capacidade de revisão e ajuste ao longo do tempo e considerando as projeções climáticas (e não apenas seu histórico). 


\section{Considerações finais e perspectivas}

56 O objetivo de universalização do acesso à água torna os programas P1MC, APT e Cisternas iniciativas de grande relevância na promoção do direito humano ao acesso à água e na busca da segurança hídrica e alimentar, particularmente em áreas semiáridas, onde o acesso aos serviços básicos é marcado por desigualdades sociais e políticas. Estudos que demonstram as vantagens e desvantagens de cada tipo de tecnologia ainda carecem de avaliações mais sistemáticas. Ainda assim, a cisterna é sinônimo de autonomia, independentemente do tipo de tecnologia e do acesso a outro tipo de abastecimento, oferecendo um acesso mínimo à água para famílias rurais do Semiárido. Sua eficácia, porém, depende do uso sustentável da água e da compreensão pelas famílias sobre os limites de armazenamento em período de estiagem e sobre o tratamento da água para consumo.

No entanto, a redução das vulnerabilidades socioambientais requer abordagens mais amplas e transformadoras que vão além da distribuição de infraestruturas hídricas. A mobilização social e a formação para a gestão descentralizada da água contribuem para ampliar o impacto e os ganhos sociais da tecnologia e, portanto, merecem ser mantidas e aprofundadas. Assistência técnica para construção e manutenção das cisternas e outros tipos de infraestrutura, formação das famílias para garantia da manutenção da cisterna e da qualidade da água armazenada, cultivo de alimentos saudáveis, além do fortalecimento da organização social, incluindo a transversalização da questão de gênero nos diversos ciclos da integração das políticas públicas em nível local, são alguns dos aspectos capazes de serem fortalecidos. As tecnologias sociais têm o potencial de aprofundar o debate sobre os contextos locais e políticos, que são a base de qualquer estratégia de redução das vulnerabilidades.

58 As divergências e os conflitos observados na evolução dos programas de distribuição de cisternas não se limitam ao tipo de material empregado, mas a concepções e projetos de desenvolvimento e a atores políticos. A resposta tem sido a manutenção de ambas estratégias de forma paralela. A bricolagem institucional foi o caminho encontrado para formulação de desenhos de políticas baseados em experiências de sucesso concebidas a partir de novos (re)arranjos institucionais delineados para diferentes escalas e modelos de governança concebidos a partir de realidades menos complexas. $O$ aumento da escala ainda é um dos grandes desafios e esbarra na tentativa de replicar iniciativas locais ou regionais de sucesso para realidades de maior alcance, sob pena de seus desenhos metodológicos apresentarem pouca efetividade. Diante deste contexto, a compreensão das implicações políticas causadas pela mudança de estratégia a partir do lançamento do APT é relevante para se avançar nos processos de negociação e de formulação de iniciativas mais efetivas.

59 Finalmente, mas não menos importante, vale destacar a diminuição crescente dos recursos destinados nos últimos anos aos programas aqui analisados, resultando na descontinuidade dos arranjos institucionais apresentados e na próxima execução das políticas. As justificativas são de várias naturezas. Estas incluem a crise fiscal entre União, estados e municípios e tangenciam a crise das instituições democráticas participativas, incluindo o questionamento acerca da legitimidade e a efetividade das organizações da sociedade civil. Todavia, subjacente a todos esses aspectos há que se reconhecer que a mudança na orientação ideológica do governo federal e a opção por um projeto de desenvolvimento liberal-conservador contribuiu para marginalização 
das políticas sociais que preconizam um desenvolvimento mais democrático e inclusivo induzido pelo Estado. Tanto o processo de fragilização destas políticas, quanto seu impacto na garantia do acesso à água, e os mecanismos emergentes de resistência merecem ser analisados em uma agenda futura de pesquisa.

\section{BIBLIOGRAFIA}

Adger, Neil, « Vulnerability ». Global Environmental Change 16 (3), 2006, p.268-81.

Agência Nacional de Águas. Conjuntura dos Recursos Hídricos no Brasil. Brasília: ANA, 2013.

Andrade, Jackeline Amantino, e Cordeiro, José Raimundo, « Uma discussão sobre a possibilidade da criação institucional e sinergia entre Estado e sociedade: o caso do P1MC no Semiárido brasileiro ", Cadernos EBAPE, BR 14, 2016, p.551-68.

Andrade, Jucilaine, e Nunes, Marcos Antônio, « Acesso à água no Semiárido Brasileiro: uma análise das políticas públicas implementadas na região », Revista Espinhaço, UFVJM, março 2017, p. 28-39.

Andrade, Tafne et al. Estratégias de adaptação e gestão do risco: o caso das cisternas no semiárido brasileiro. Climacom Cultura Científica - Pesquisa, Jornalismo e Arte, a. 2, vol. 2, 2015. ASA, « Cisternas de PVC: solução ou armadilha? » Panfleto, Recife: Articulação do Semiárido, 2011. Bonnal, Philippe, e Piraux, Marc, « Actions publiques territoriales en milieu rural et innovations ", 12, 2010.

Bursztyn, Marcel, e Chacon, Suely, «Ligações perigosas: proteção social e clientelismo no Semiárido Nordestino ", Estudos Sociedade e Agricultura, Rio de Janeiro, vol. 19, n 1, 2011, p.30-61.

Bursztyn, Marcel, o poder dos donos: Planejamento e clientelismo no Nordeste, 3a edição, Rio de Janeiro, Garamond, 2008.

Campos, Arnoldo, e Melo Alves, Adriana, «O Programa Água para Todos: ferramenta poderosa contra a pobreza », In O Brasil sem miséria, organizado por Tereza Campello, Tiago Falcão, e Patricia Vieira da Costa, 1a edição, 2014, p.467-92. Brasília: Ministério do Desenvolvimento Social e Combate à Fome.

Cardoso, Gil, A Atuação do Estado no Desenvolvimento Recente do Nordeste, João Pessoa, Editora Universitária, 2007.

De Nys, Erwin, e Lee Engle, Nathan, « Convivência com o Semiárido e Gestão proativa da seca no Nordeste do Brasil: Uma nova Perspectiva », The World Bank, 2014.

Gandure, Sithabiso, Walker, Sue, Botha, Jacobus, « Farmers' perceptions of adaptation to climate change and water stress in a South African rural community », Environmental Development, vol. 5, p. 39-53, 2013.

Gnadingler, Johann, « Apresentação técnica de diferentes tipos de cisternas, construídas em comunidades rurais do semiárido brasileiro » In: Anais da 9a Conferência Internacional sobre Sistemas de Captação de Agua da Chuva, Petrolina, 1999. 
Lindblom, Charles E. « Still Muddling, Not Yet Through. » Public Administration Review 39, $\mathrm{n}^{\circ} 6$, 1979. https://doi.org/10.2307/976178.

Marengo, Jose, Cunha, Ana Paula, Soares, Wagner, et al., «Increase Risk of Drought in the Semiarid Lands of Northeast Brazil Due to Regional Warming above $4^{\circ} \mathrm{C} »$, In Climate Change Risks in Brazil, organizado por Carlos A. Nobre, Jose A. Marengo, e Wagner R. Soares, 2019, p. 181-200. Springer International Publishing.

Martins, Minella, Hochrainer-Stigler, Stefan, e Pflug, Georg, « Vulnerability of Agricultural Production in the Brazilian Semi-Arid: An Empirical Approach Including Risk », 2017, p.23.

MDS, Tabela - Programa Água para Todos - Tecnologias de captação de água entregues no Semiárido de 2003 a fev/2016, 2016, http://mds.gov.br/area-de-imprensa/noticias/2016/marco/cisternasgarantem-agua-seguranca-alimentar-e-vida-digna-aos-sertanejos/apt-fev2016.png/view, acesso efectuado em 14/01/2020.

MI, Programa Água para Todos - Os objetivos do programa, 2012, http://mi.gov.br/web/guest/ objetivos, acesso efectuado em 14/01/2020.

MI, « Perguntas Frequentes: programa Água para Todos - Quais as características da cisterna de polietileno? » 2011, http://mi.gov.br/perguntas-frequentes\#AGT12, acesso efectuado em $14 / 01 / 2020$

MPDG, PPA Cidadão - Programa 2069 Segurança Alimentar e Nutricional - Relatório de Avaliação do Programa, 2017, https://ppacidadao.planejamento.gov.br/sitioPPA/paginas/todo-ppa/ objetivos.xhtml?programa=2069\&ep=1, acesso efectuado em 14/01/2020. .

Milhorance, Carolina, Sabourin, Eric, Mendes, Priscylla, « Adaptation to climate change and policy interactions in Brazil's semiarid region », Montreal, 4th International Conference on Public Policy, 2019a.

Milhorance, Carolina, Mendes, Priscylla, Patrícia Mesquita, et al., « O desafio da integração de políticas públicas para a adaptação às mudanças climáticas no Semiárido brasileiro », Revista Brasileira de Climatologia, Ano 15, vol. 24, 2019 b.

Morais, Hugo Azevedo Rangel de, Paiva, Juarez Azevedo de, e Sousa, Washington José de, « Avaliação do Programa Um Milhão de Cisternas Rurais: eficácia, eficiência e efetividade nos territórios do Rio Grande do Norte (2003/2015) », Revista de Políticas Públicas 21 (1), 2017, p.133-58.

Nóbrega, Rodolfo, et al., « Água de chuva para uso doméstico », In: Galvão, C.O. et al., Recursos hídricos para a convivência com o semiárido: abordagens sobre o semiárido por pesquisadores no Brasil, Portugal, Cabo Verde, Estados Unidos e Argentina. Porto Alegre: ABRH; Recife: Editora Universitária UFPE, p.377-394, 2013.

Nogueira, Daniela, « Segurança Hídrica, Adaptação e Gênero: o caso das cisternas para captação de água de chuva no Semiárido brasileiro ». Sustentabilidade em Debate, vol. 8, n 3, p.22-36, dez. 2017.

Nogueira, Daniela, « Femmes et eau dans le Sertão. Le programme Un million de citernes ", Cahiers des Amériques Latines, 63-64, 2010, 2013, http://journals.openedition.org/cal/790; DOI: 10.4000/cal.790, 2013.

Nogueira, Daniela, « Gênero e Água - Desenhos do Norte, Alternativas do Sul: análise da experiência do Semiárido brasileiro na construção do desenvolvimento democrático ». Tese de Doutorado, Brasília: Universidade de Brasília, 2009. 
Mota, Daniel Martins Papini; Vianna, Marcos Rocha e Lacerda, Kássio André, « Avaliação das cisternas para armazenagem de água pluvial, construídas de placas cimentícias pré-moldadas, implantadas no interior do estado de Minas Gerais ». Lisboa, 2016.

Pereira, Maria Cecília, « Água e convivência com o Semiárido: múltiplas águas, distribuições e realidades », Tese de doutorado, Fundação Getúlio Vargas, 2016.

Rasella, Davide, «Impacto do Programa Água para Todos (PAT) sobre a morbi-mortalidade por diarreia em crianças do Estado da Bahia, Brasil », Cadernos de Saúde Pública 29 (1), 2013, p.40-50.

Rodriguez, Renata, Pruski, Fernando e Singh, Vijay, « Estimated Per Capita Water Usage Associated with Different Levels of Water Scarcity Risk in Arid and Semiarid Regions ». Water Resources Management 30 (4), 2016, p.1311-24.

Santana, Vitor; Arsky, Igor e Soares, Carlos, « Democratização do acesso à água e desenvolvimento local: a experiência do Programa Cisternas no Semiárido brasileiro. » Anais do I circuito de debates acadêmicos, 2011.

Schmitt, João Felipe, « Adoção e inovação no combate à seca no semiárido: um estudo com os usuários de cisternas de polietileno nos municípios de Trairi-CE e Caucaia-CE », Fortaleza, Universidade Estadual do Ceará, 2015.

Silva, Bruce; Amorim, Ana Cleide; Silva, Claudio; Lucio, Paulo; e Barbosa, Lara, « Rainfall-Related Natural Disasters in the Northeast of Brazil as a Response to Ocean-Atmosphere Interaction ». Theoretical and Applied Climatology, julho 2019.

Silva, Darly, Combate à desertificação e a COP dos Pobres. Terceiro incluído, NUPEAT-IESA-UFG, vol. 4, n 1, Jan./Jun., p.1-23, 2014. Silva, João Paulo, « Políticas públicas de enfrentamento à problemática da seca no Semiárido mineiro: uma análise do programa água para todos na perspectiva da avaliação de quarta geração ", Dissertação de Mestrado, Belo Horizonte, Universidade Federal de Minas Gerais, 2017.

TCU, « Relatório de avaliação de programa: Ação Construção de Cisternas para Armazenamento de Água. » Relator Ministro Guilherme Palmeira. Brasília, Tribunal de Contas da União, Secretaria de Fiscalização e Avaliação de Programas de Governo, 2006. 


\section{ANEXOS}

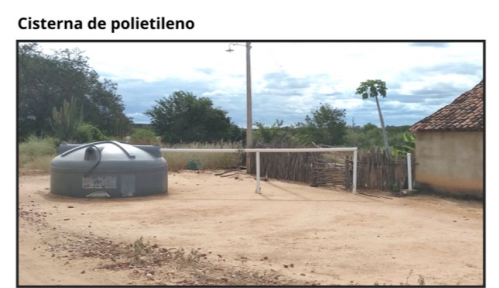

Cisterna de placa

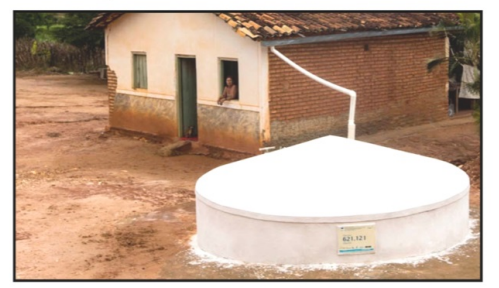

Cisterna produtiva

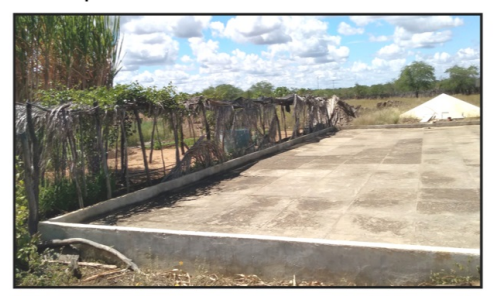

Fonte: Autores e ASA Brasil

\section{NOTAS}

1. Ministério precursor do MDS, criado em 2004.

\section{RESUMOS}

A universalização do acesso das populações rurais à água permanece um desafio em regiões como o Semiárido brasileiro. Uma série de políticas públicas, em especial o Programa Um Milhão de Cisternas, tem contribuído desde o início dos anos 2000 para alcançar este objetivo, promovendo a construção de cisternas de captação de água da chuva. Apesar dos resultados de ampliação do acesso à água e do grau de inovação do seu desenho metodológico, mudanças significativas na concepção e no arranjo político-institucional do programa foram observadas a partir de 2011, com a criação do Água para Todos. Com base em dados secundários, relatórios de avaliação e entrevistas com gestores federais e locais nos estados da Bahia e Pernambuco, o presente artigo examina o processo político que levou a tal mudança, trazendo para o centro da discussão suas motivações, evolução e as implicações. Além do interesse analítico de um processo de mudança programática e de disputa entre burocracias estatais, incluindo suas dinâmicas de alianças com atores sociais, o artigo discute os desafios de formulação de políticas públicas e de sua 
implementação em nível local. Por fim, o programa é discutido sob uma perspectiva mais ampla de redução das vulnerabilidades socioambientais e de necessidade de ajustes frente a desafios decorrentes das mudanças climáticas globais.

The universalization of access to water in rural communities remains a challenge in regions like the Brazilian semi-arid. Several public policies, especially the One Million Cisterns Program, has contributed since the beginning of the 2000s to achieve these goals by promoting the establishment of rainwater catchment cisterns. Despite the results in terms of increase of the access to water and the degree of innovation in its methodological design, significant changes in the conception and political-institutional arrangement of the program were observed from 2011 onwards, with the creation of the Water for All Program. Based on secondary data, evaluation reports and interviews with national and subnational managers in the states of Bahia and Pernambuco, this article examines the political process that led to such change, shedding light on its motivations, evolution and implications. In addition to the interest of analysing a process of programmatic change and dispute between state bureaucracies, including their patterns of alliances with social actors, the article discusses the challenges of policy formulation and implementation at the local level. Finally, the program is discussed with regard to the reduction of socio-environmental vulnerabilities and the need for adjustments in the face of global climate change challenges.

L'universalisation de l'accès à l'eau pour les populations rurales reste un défi dans des régions telles que la région semi-aride du Brésil. Une série de politiques publiques, notamment le programme "Un million de citernes", a contribué depuis le début des années 2000 à atteindre cet objectif en préconisant la construction de citernes de collecte des eaux de pluie. Malgré les résultats atteints en matière d'élargissement de l'accès à l'eau et le degré d'innovation dans sa conception méthodologique, des changements significatifs dans la conception et l'arrangement politico-institutionnel du programme ont été observés à partir de 2011, avec la création du programme "Eau pour tous". En se fondant sur des données secondaires, des rapports d'évaluation et des entretiens avec des responsables fédéraux et locaux dans les états de Bahia et de Pernambuco, cet article examine le processus politique qui a conduit à ce changement, en plaçant ses motivations, son évolution et ses implications au centre de la discussion. Outre l'intérêt analytique d'un processus de changement programmatique et de conflit entre les bureaucraties étatiques, notamment leur dynamique d'alliances avec les acteurs sociaux, l'article aborde les défis de la formulation et de la mise en œuvre des politiques publiques au niveau local. Enfin, le programme est examiné sous une optique plus large de réduction des vulnérabilités socio-environnementales et de la nécessité de procéder à des ajustements face aux défis du changement climatique mondial.

\section{ÍNDICE}

Mots-clés: Brésil, eau, arrangements institutionnels, vulnérabilité, semi-aride.

Keywords: Brazil, water, institutional arrangements, vulnerability, semiarid.

Palavras-chave: Brasil, água, arranjos institucionais, vulnerabilidade, Semiárido. 


\section{AUTORES}

\section{DANIELA NOGUEIRA}

Daniela Nogueira é pesquisadora associada e pós-doutoranda do Centro de Desenvolvimento Sustentável da Universidade de Brasília onde participa da Rede-Clima e do Projeto INCT-Odisseia - Observatório das Dinâmicas Socioambientais. Sua área de pesquisa concentra-se nas políticas de adaptação às mudanças climática, vulnerabilidades socioambientais e capacidade adaptativa; governança global para segurança hídrica com perspectiva de gênero e gestão participativa. Coordenou o Dossiê Gênero: uma abordagem necessária à gestão das águas da Revista Sustentabilidade em Debate, v.8, n.3, 2017 e publicou recentemente o livro "Objetivo de Desenvolvimento Sustentável 6 - Água e Saneamento: estudos e proposição de medidas para implementação e monitoramento da Agenda 2030 no Brasil", Brasília: IPEA, 2019 (no prelo). danielanogueira@gmail.com

\section{CAROLINA MILHORANCE}

Carolina Milhorance é pós-doutoranda do Centro de Desenvolvimento Sustentável da Universidade de Brasília. Seus trabalhos de pesquisa têm como foco as políticas de adaptação às mudanças climáticas e vulnerabilidades socioambientais no Brasil; a cooperação sul-sul no setor rural e o papel das organizações internacionais na transferência de políticas públicas. Publicou recentemente o livro: "New Geographies of Global Policy-Making: South-South Networks and Rural Development Strategies”, Routledge: New York, London, 2018. cmilhorance@gmail.com

\section{PRISCYLLA MENDES}

Priscylla Mendes é doutoranda do Centro de Desenvolvimento Sustentável da Universidade de Brasília. Participa dos projetos Rede Clima (sub-rede Desenvolvimento Regional), INCT-Odisseia Observatório das Dinâmicas Socioambientais e Artimix (Articulação das Políticas de Adaptação às Mudanças Climáticas na América Latina e no Caribe). Desenvolve pesquisa sobre interação de políticas de adaptação e de mitigação às mudanças climáticas para agricultura familiar na Bacia do São Francisco. Sua mais recente publicação foi o capítulo "Clima, políticas públicas e adaptação: vulnerabilidades em três contextos", do livro Agricultura de baixa emissão de carbono em regiões semiáridas - experiência brasileira, Petrolina: Embrapa Semiárido, 2019 (no prelo). priscylladayser@hotmail.com 